Case Report

\title{
Application of Hybrid Extracorporeal Membrane Oxygenation for the Treatment of Subsequent Shock following Acute Respiratory Distress Syndrome Developing after Firearm Injury
}

\author{
Yahya Yildiz, ${ }^{1}$ Didem Melis Oztas, ${ }^{2}$ Mustafa Ozer Ulukan, ${ }^{3}$ Korhan Erkanli, ${ }^{3}$ Orcun Unal, ${ }^{4}$ \\ Murat Ugurlucan $\left(\mathbb{0},{ }^{3}\right.$ and Halil Turkoglu ${ }^{3}$ \\ ${ }^{1}$ Istanbul Medipol University Medical Faculty, Department of Anesthesiology, Istanbul, Turkey \\ ${ }^{2}$ Bagcilar Training and Research Hospital, Department of Cardiovascular Surgery, Istanbul, Turkey \\ ${ }^{3}$ Istanbul Medipol University Medical Faculty, Department of Cardiovascular Surgery, Istanbul, Turkey \\ ${ }^{4}$ Yedikule Chest Diseases and Thoracic Surgery Education and Research Hospital, Cardiovascular Surgery Clinic, Istanbul, Turkey
}

Correspondence should be addressed to Murat Ugurlucan; muratugurlucan@yahoo.com

Received 25 May 2019; Revised 6 September 2019; Accepted 1 October 2019; Published 4 December 2019

Academic Editor: Bruno Megarbane

Copyright (C) 2019 Yahya Yildiz et al. This is an open access article distributed under the Creative Commons Attribution License, which permits unrestricted use, distribution, and reproduction in any medium, provided the original work is properly cited.

The use of extracorporeal membrane oxygenation (ECMO) in acute respiratory distress syndrome (ARDS) and cardio-circulatory shock has been widely accepted. In recent years, a variety of novel and exceptional indications for ECMO have been proposed; however, experience with ECMO use in the presence of multiple penetrating injuries is limited. In this report, we present successful ECMO application in a patient with multiple firearm injuries. Veno-venous ECMO was applied for ARDS and converted to the venoarterial mode when the patient developed septic cardiomyopathy. The clinical status of the patient gradually improved, and the patient was discharged from the hospital after 24 days, successfully.

\section{Introduction}

Worldwide extracorporeal membrane oxygenation (ECMO) use has increased for the treatment of refractory patients with acute respiratory distress syndrome (ARDS). It is applied with reasonable mortality and morbidity rates to support mechanical ventilation (MV) [1]. Prolonged and high-pressure mechanical ventilation has certain risks for the pulmonary system. The veno-venous (V-V) ECMO supports patients in such critical conditions with facilitated carbon dioxide clearance and oxygenation; hence, mortality and morbidity secondary to ARDS may be attenuated [2-4].

ECMO has also use in polytrauma patients; however, experience is limited especially due to the high risk of major uncontrollable bleeding. In addition, the success of ECMO is relatively better in case of pulmonary trauma when compared with other organ systems including brain and spinal cord injuries [5].
In this report, we present our successful ECMO experience in a patient with multiple gunshot injuries.

\section{Case Report}

A 45-year-old male patient was brought to the emergency department at 01:00 a.m. in unconscious status with multiple gunshot injuries. He weighed $70 \mathrm{~kg}$ and was $168 \mathrm{~cm}$ tall. The patient was paraplegic. One of the bullets entered from the left arm pit and left the body from the right scapula. There was another bullet entrance from the right upper abdominal quadrant. His relatives did not present any history of previous medical issues or regular use of medications. Chest roentgenogram and computerized tomography scans indicated hemopneumothorax in the left hemithorax with destruction of the upper lobe of the left lung. In addition, the vertebral corpuses of T4 and T5 were severely destructed. There were liver and spleen injuries with intra-abdominal fluid accumulation. 
A chest tube was inserted emergently into the left hemithorax and revealed $650 \mathrm{ml}$ hemorrhagic fluid drainage and resulted in expansion of the lung. He was intubated, and vertebral stabilization surgery, as well as laparotomy to treat hepatic and splenic lacerations was performed. The patient was followed at the intensive care unit, however could not be extubated. His status deteriorated on the third day $\left(\mathrm{PaO}_{2} /\right.$ $\mathrm{FiO}_{2}$ became 154). Endotracheal aspiration and wound cultures resulted negative. The appearance of the lungs worsened on chest roentgenograms, and we diagnosed him as ARDS according to the ARDS Berlin Criteria. Despite various mechanical ventilation and physiotherapy attempts, the status of the lungs did not improve and $\mathrm{PaO}_{2} / \mathrm{FiO}_{2}$ ratio became 53 and pulmonary compliance decreased to $18 \mathrm{ml} / \mathrm{cmH}_{2} \mathrm{O}$. We decided to institute $\mathrm{V}-\mathrm{V}$ ECMO with echocardiography guidance [6], despite the risk of bleeding due to multiple penetrating injuries and recent surgical treatment. ECMO flow was adjusted to $2 \mathrm{lt} / \mathrm{min}$ at a rate of $9,000 \mathrm{rpm}$, mechanic ventilator $\mathrm{FiO}_{2}$ of 0.6 , positive end-expiratory pressure (PEEP) of $12 \mathrm{cmH}_{2} \mathrm{O}$, tidal volume of $420 \mathrm{ml}$, peak inspirium pressure of (PIP) $24 \mathrm{mmH}_{2} \mathrm{O}$, and inspiration/expiration ratio of $1 / 1$ which were adjusted according to the blood gas analysis. However, we needed to gradually increase the flow of ECMO to $6 \mathrm{lt} / \mathrm{min}$ due to worsening of oxygenation. $\mathrm{V}-\mathrm{V}$ ECMO in conjunction with mechanic ventilation provided sufficient gas exchange (Figure 1).

The patient developed septic cardiomyopathy which was confirmed with echocardiography indicating severely depressed myocardial functions (ejection fraction of 35\%) on the postoperative 13th day, despite wide-spectrum antibiotherapy with vancomycin and meropenem. Although cultures were negative, white blood cell count increased to $19 / \mathrm{uL}$, thrombocyte count decreased to 66/uL, CRP increased to $234 \mathrm{mg} / \mathrm{L}$, procalcitonin increased to $8.5 \mathrm{ng} / \mathrm{ml}$, and total bilirubin and direct bilirubin levels increased to $18 \mathrm{mg} / \mathrm{dl}$ and $16 \mathrm{mg} / \mathrm{dl}$, respectively. His inotropic score gradually increased to 40 and we decided veno-arterio-venous (hybrid) ECMO with addition of V-A ECMO to the femoral artery and vein. The deterioration in patient's hemodynamics, echocardiography findings, and blood gas analysis are presented in Table 1.

His status gradually improved in time and he was weaned off $\mathrm{V}-\mathrm{A}-\mathrm{V}$ ECMO with rapid consecutive conversion to V-V ECMO for a few hours and then completely disconnected on the 20th day with decreased leucocyte count $(9 / \mathrm{uL})$, increased thrombocyte count $(163 / \mathrm{uL})$, decreased CRP (63), and decreased total bilirubin (3/uL) levels. His mechanical ventilation parameters were $\mathrm{FiO}_{2} 0.5, \mathrm{P} / \mathrm{F}$ 262, PEEP $8 \mathrm{cmH}_{2} \mathrm{O}$, TV $450 \mathrm{ml}$, PIP $23 \mathrm{cmH}_{2} \mathrm{O}, \mathrm{I} / \mathrm{E} 1 / 2$, and compliance $37 \mathrm{ml} / \mathrm{cmH}_{2} \mathrm{O}$ which were confirmed with chest $\mathrm{X}$-ray (Figure 2). Two days after, he was in stable conditions, and percutaneous tracheostomy was performed. He was discharged from the intensive care unit and from the hospital on the 24 th day and one week after, respectively.

\section{Discussion}

Acute respiratory distress syndrome is a kind of pulmonary edema which occurs due to acute inflammatory diffuse lung

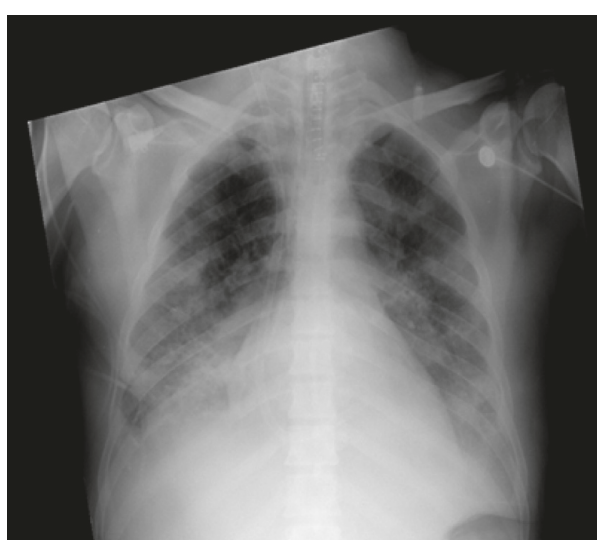

FIGURE 1: Chest roentgenogram following V-V ECMO institution with right jugular venous cannulation.

damage resulting in increase in pulmonary capillary permeability and fluid passage into the thoracic cavity. In this condition, the reasons that damage alveolocapillary membrane are pneumonia, sepsis in accordance with direct aspiration into the airways, and indirect heamatogenous exposure of embolism to the lungs [7].

Due to the high mortality rates of ARDS, rapid diagnosis and early mechanic ventilation are recommended in accordance with the criteria established by the American Thorax Foundation and European Intensive Care Foundation joint meeting (American-European Consensus Conference-AECC) in 1994. These criteria include an acute hypoxemia without concerning the PEEP level, the P/F ratio lesser than 200, bilateral diffuse infiltrations on chest roentgenogram, and pulmonary artery wedge pressure (PAWP) lesser than $18 \mathrm{mmHg}$. Also, the condition should not be secondary to the left heart failure. In cases of $\mathrm{P} / \mathrm{F}$ ratios exceeding 200 and being lower than 300 , the condition is diagnosed as acute lung injury [2].

Mechanical ventilation is a lifesaving system in patients with ARDS which enables gas exchange, whilst it may increase the pulmonary damage and increase the mortality rate. Open lung ventilation strategy with alveolar opening maneuvers and personally titrated PEEP and low tidal density support hyperventilation strategy allowing approach may attenuate mechanical ventilation-related pulmonary damage. This protocol was established in Permissive Hypercapnia, Alveolar Recruitment and Low Airway Pressure (PHARLAP) working principles, but the results remained limited [8].

According to the ARDS Berlin criteria and the clinic severity classification in mortality, the duration of ventilation and lung weight have changed drastically in such conditions. The Berlin criteria do not propose PAWP measure. Instead, it is stated that increased hydrostatic pressure is a primary source of respiratory issues, and this is outed by methods like ECMO [9]. In our case, given that the $\mathrm{P} / \mathrm{F}$ value was $<100$ and $\mathrm{PEEP}>5$, this was included into the severe class in Berlin criteria. Also, the lung compliance decreased as low as $18 \mathrm{ml} / \mathrm{cmH}_{2} \mathrm{O}$ and $\mathrm{P} / \mathrm{F}$ ratio to 53 . Prone position was also applied for better ventilation [10]. In order to obtain better oxygenation, we instituted V-V ECMO to 
TABLE 1: Clinical parameters of the patient.

\begin{tabular}{|c|c|c|c|c|}
\hline & $\begin{array}{l}\text { After the } \\
\text { intubation }\end{array}$ & $\begin{array}{l}\text { Before the V-V } \\
\text { ECMO }\end{array}$ & $\begin{array}{c}\text { Before the } \mathrm{V}-\mathrm{A}-\mathrm{V} \\
\text { ECMO }\end{array}$ & $\begin{array}{c}\text { Disconnection from } \mathrm{V}-\mathrm{A}-\mathrm{V} \\
\text { ECMO }\end{array}$ \\
\hline \multicolumn{5}{|l|}{ Ventilation parameters } \\
\hline $\mathrm{TV}(\mathrm{ml} / \mathrm{kg})^{1}$ & $6-8$ & 6 & 6 & $6-8$ \\
\hline $\operatorname{PEEP}\left(\mathrm{cmH}_{2} \mathrm{O}\right)$ & 5 & $12-14$ & $8-10$ & 6 \\
\hline PIP $\left(\mathrm{cmH}_{2} \mathrm{O}\right)$ & 22 & 38 & 32 & 26 \\
\hline $\mathrm{FiO}_{2}$ & $0.4-0.6$ & 1 & 0.4 & 0.4 \\
\hline \multicolumn{5}{|l|}{ Inotropes $(\mathrm{mcg} / \mathrm{kg} / \mathrm{min})$} \\
\hline Adrenaline & 0.05 & 0.1 & 0.10 & 0.05 \\
\hline Noradrenaline & 0.05 & 0.05 & 0.20 & 0.1 \\
\hline Milrinone & & & 0.5 & \\
\hline Dobutamine & & & 5 & \\
\hline \multicolumn{5}{|l|}{ Blood gas analysis } \\
\hline $\mathrm{pH}$ & $\mathrm{N}$ & 7.24 & $7.26-7.40$ & $\mathrm{~N}$ \\
\hline $\mathrm{PaCO}_{2}(\mathrm{mmHg})$ & $\mathrm{N}$ & 86 & & $\mathrm{~N}$ \\
\hline $\mathrm{PaO}_{2}(\mathrm{mmHg})$ & 86 & 53 & & \\
\hline Lactate $(\mathrm{mmol} / \mathrm{L})$ & $1.8-2.7$ & $3.6-5.2$ & $16-20$ & $\mathrm{~N}$ \\
\hline Urinary output $(\mathrm{ml} / \mathrm{kg} / \mathrm{h})$ & $1-3$ & $0.3-1$ & $0.2-1$ & $2-3$ \\
\hline $\begin{array}{l}\text { Prone position and recruitment } \\
\text { maneuvers }\end{array}$ & No & Yes & No & No \\
\hline
\end{tabular}

ECMO: extracorporeal membrane oxygenation, V-V: veno-venous, V-A-V: veno-arterio-venous, TV: tidal volume, PEEP: positive end-expiratory pressure, PIP: peak inspirium pressure, $\mathrm{FiO}_{2}$ : fractional inspired oxygen, $\mathrm{PaO}_{2}$ : partial oxygen pressure, $\mathrm{PaCO}_{2}$ : partial carbon dioxide pressure, and $\mathrm{N}$ : normal.

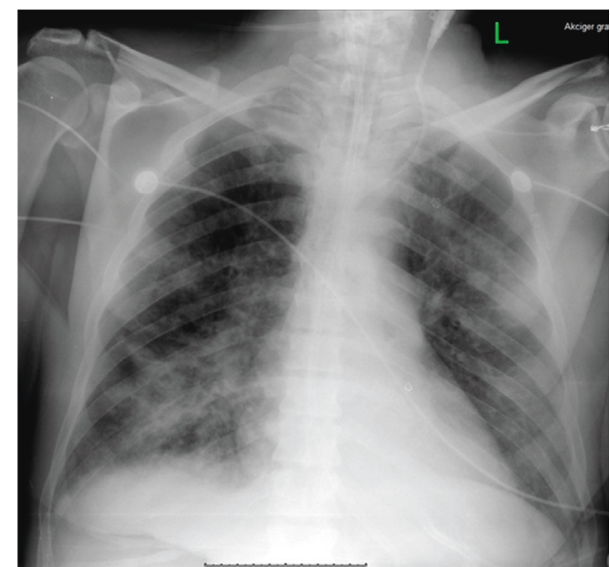

FIGURE 2: Chest roentgenogram of the patient after weaning off the ECMO.

the patient and adjusted mechanic ventilator parameters in order to prevent further pulmonary damage [11], despite the risk of bleeding due to multiple penetrating injuries and the surgical procedures. Severe bleeding was prevented by rigorous use of blood and blood products as well as with coagulation factors when needed. Since his condition deteriorated due to septic cardiogenic shock, we added V-A ECMO to V-V ECMO strategy in conjunction as a hybrid therapy as an established method in the literature [12]. Additional V-A ECMO was instituted through the femoral artery and vein with a 5F distal femoral line for leg perfusion [13].

Midazolam and fentanyl with appropriate sedation and adequate analgesia $(\mathrm{VAS}<3$ ) were provided at the intensive care unit [14]. Parenteral and low amount of enteral nutrition were started while on ECMO and continued in accordance with research that presented lower mortality with early enteral nutrition [15]. When the condition of the patient got better, we decided to wean him off hybrid ECMO. First, the femoral artery was decanulated and V-V ECMO flow was decreased to $<2 \mathrm{lt} / \mathrm{min}$, after 4 hours to $<1 \mathrm{lt} / \mathrm{min}$, and ECMO FiO2 was decreased to $25 \%$ of systematic flow. A shunt was implemented between venous and arterial lines. Four hours later, the hemodynamics and oxygenation were promising with mechanical ventilation goals, and V-V ECMO was stopped and sole mechanical ventilation was started [10]. After the cessation of ECMO, the systemic heparinization that was required during ECMO was stopped, and the patient was treated with low-molecular weight heparin for prophylaxis against pulmonary embolism or thromboembolism from the ECMO-inserted vessels $[16,17]$.

In conclusion, despite our single case experience, we managed our polytrauma patient with consecutive mechanical ventilation, when failed with $\mathrm{V}-\mathrm{V}$ ECMO and when septic cardiomyopathy occurred in conjunction with $\mathrm{V}-\mathrm{A}-\mathrm{V}$ hybrid ECMO strategy, successfully, despite the high risk of bleeding which was prevented by rational use of blood and blood products as well as coagulation factors when needed. Our measures and successful workup prevented further damage in an already injured lung and saved the life of the patient when septic cardiomyopathy occurred without causing severe uncontrollable bleeding.

\section{Conflicts of Interest}

The authors declare that they have no conflicts of interest.

\section{Acknowledgments}

The authors convey sincere gratitude to Mr. Robert Moore for the linguistic revision of the manuscript. 


\section{References}

[1] F. Pappalardo and A. Montisci, "Adjunctive therapies during veno-venous extracorporeal membrane oxygenation," Journal of Thoracic Disease, vol. 10, no. S5, pp. S683-S691, 2018.

[2] V. M. Ranieri, G. D. Rubenfeld, B. T. Thompson et al., "Acute respiratory distress syndrome: the Berlin definition. ARDS definition task force," JAMA, vol. 307, no. 23, pp. 2526-2533, 2012.

[3] M. Y. Wu, C. C. Huang, T. I. Wu, C. L. Wang, and P. J. Lin, "Venovenous extracorporeal membrane oxygenation for acute respiratory distress syndrome in adults: prognostic factors for outcomes," Medicine (Baltimore), vol. 95, no. 8, p. e2870, 2016.

[4] P. L. Bosarge, L. A. Raff, G. McGwin Jr. et al., "Early initiation of extracorporeal membrane oxygenation improves survival in adult trauma patients with severe adult respiratory distress syndrome," Journal of Trauma and Acute Care Surgery, vol. 81, no. 2, pp. 236-243, 2016.

[5] C. Y. Chen, T. Y. Hsu, W. K. Chen, C. H. Muo, H. C. Chen, and H. M. Shih, "The use of extracorporeal membrane oxygenation in trauma patients: a national case-control study," Medicine (Baltimore), vol. 97, no. 36, Article ID e12223, 2018.

[6] D. W. Donker, C. L. Meuwese, S. A. Braithwaite et al., "Echocardiography in extracorporeal life support: a key player in procedural guidance, tailoring and monitoring," Perfusion, vol. 33, no. 1_suppl, pp. 31-41, 2018.

[7] G. R. Broomé, A. Artigas, K. L. Brigham et al., "The AmericanEuropean Consensus Conference on ARDS. Definitions, mechanisms, relevant outcomes, and clinical trial coordination," American Journal of Respiratory and Critical Care Medicine, vol. 149, no. 3, pp. 818-824, 1994.

[8] C. Hodgson, D. J. Cooper, Y. Arabi et al., "Permissive hypercapnia, alveolar recruitment and low airway pressure (PHARLAP): a protocol for a phase 2 trial in patients with acute respiratory distress syndrome. PHARLAP study investigators and the Australian and New Zealand intensive care society clinical trials group," Critical Care \& Resuscitation Journal, vol. 20, no. 2, pp. 139-149, 2018.

[9] P. Daher, P. G. Teixeira, T. B. Coopwood et al., "Mild to moderate to severe: what drives the severity of ARDS in trauma patients?," The American Journal of Surgery, vol. 84, no. 6, pp. 808-812, 2018.

[10] W. Y. Kim, B. J. Kang, C. R. Chung et al., "Prone positioning before extracorporeal membrane oxygenation for severe acute respiratory distress syndrome: a retrospective multicenter study," Medicina Intensiva, vol. 43, no. 7, pp. 402-409, 2019.

[11] Z. Zhongheng, W.-J. Gu, K. Chen, and H. Ni, "Mechanical ventilation during extracorporeal membrane oxygenation in patients with acute severe respiratory failure," Canadian Respiratory Journal, vol. 2017, Article ID 1783857, 10 pages, 2017.

[12] D. J. Vogel, J. Murray, A. Z. Czapran et al., "Veno-arteriovenous ECMO for septic cardiomyopathy: a single-centre experience," Perfusion, vol. 33, no. 1_suppl, pp. 57-64, 2018.

[13] A. Camporota, T. Bobka, S. Khin et al., "Distal perfusion cannulation and limb complications in venoarterial extracorporeal membrane oxygenation," The Journal of Extracorporeal Technology, vol. 50, no. 3, pp. 155-160, 2018.

[14] J. deBacke, E. Tamberg, L. Munshi, L. Burry, E. Fan, and S. Mehta, "Sedation practice in extracorporeal membrane oxygenation-treated patients with acute respiratory distress syndrome," ASAIO Journal, vol. 64, no. 4, pp. 544-551, 2018.
[15] H. Ohbe, T. Jo, H. Yamana, H. Matsui, K. Fushimi, and H. Yasunaga, "Early enteral nutrition for cardiogenic or obstructive shock requiring venoarterial extracorporeal membrane oxygenation: a nationwide inpatient database study," Intensive Care Medicine, vol. 44, no. 8, pp. 1258-1265, 2018.

[16] M. Matsui and A. Peris, "Deep vein thrombosis in intensive care," Advances in Experimental Medicine and Biology, vol. 906, pp. 167-181, 2017.

[17] K. Krueger, A. Schmutz, B. Zieger, and J. Kalbhenn, "Venovenous extracorporeal membrane oxygenation with prophylactic subcutaneous anticoagulation only: an observational study in more than 60 patients," Artificial Organs, vol. 41, no. 2, pp. 186-192, 2017. 


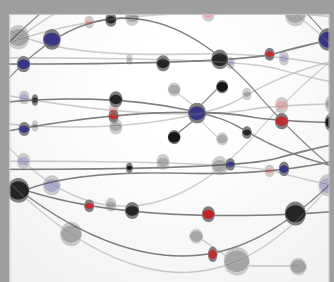

The Scientific World Journal
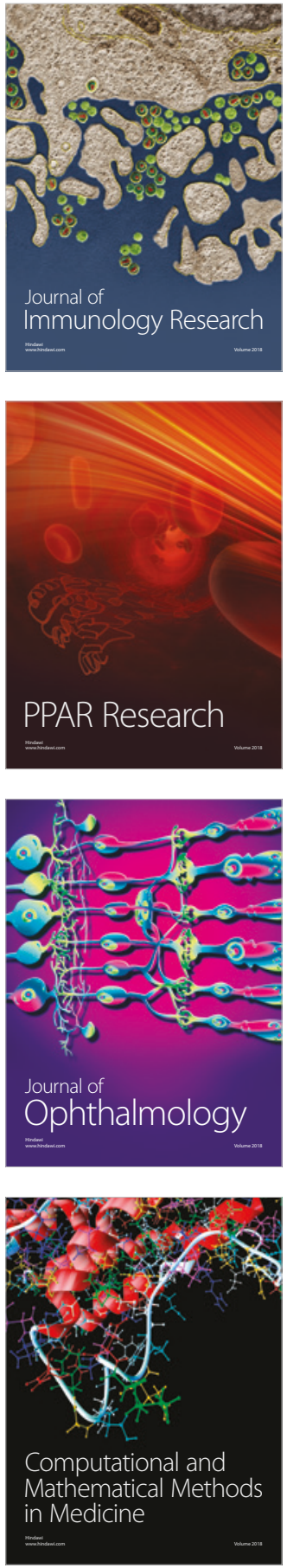

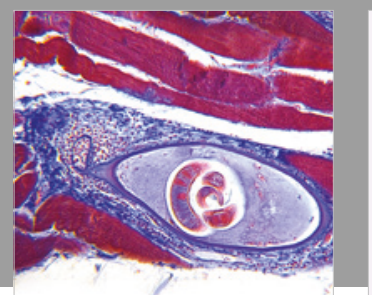

Gastroenterology Research and Practice

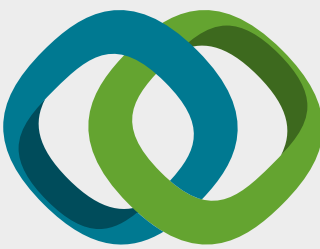

\section{Hindawi}

Submit your manuscripts at

www.hindawi.com
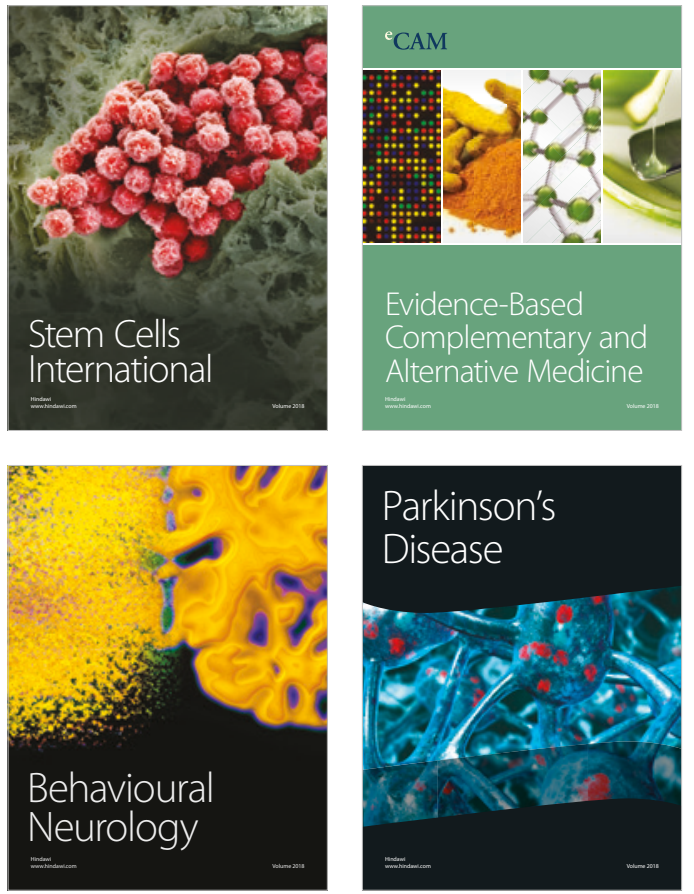

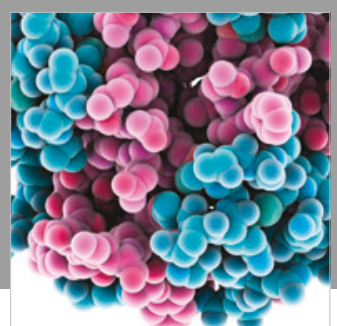

ournal of

Diabetes Research

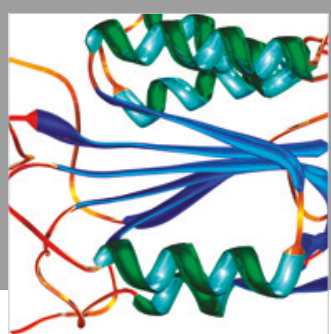

Disease Markers
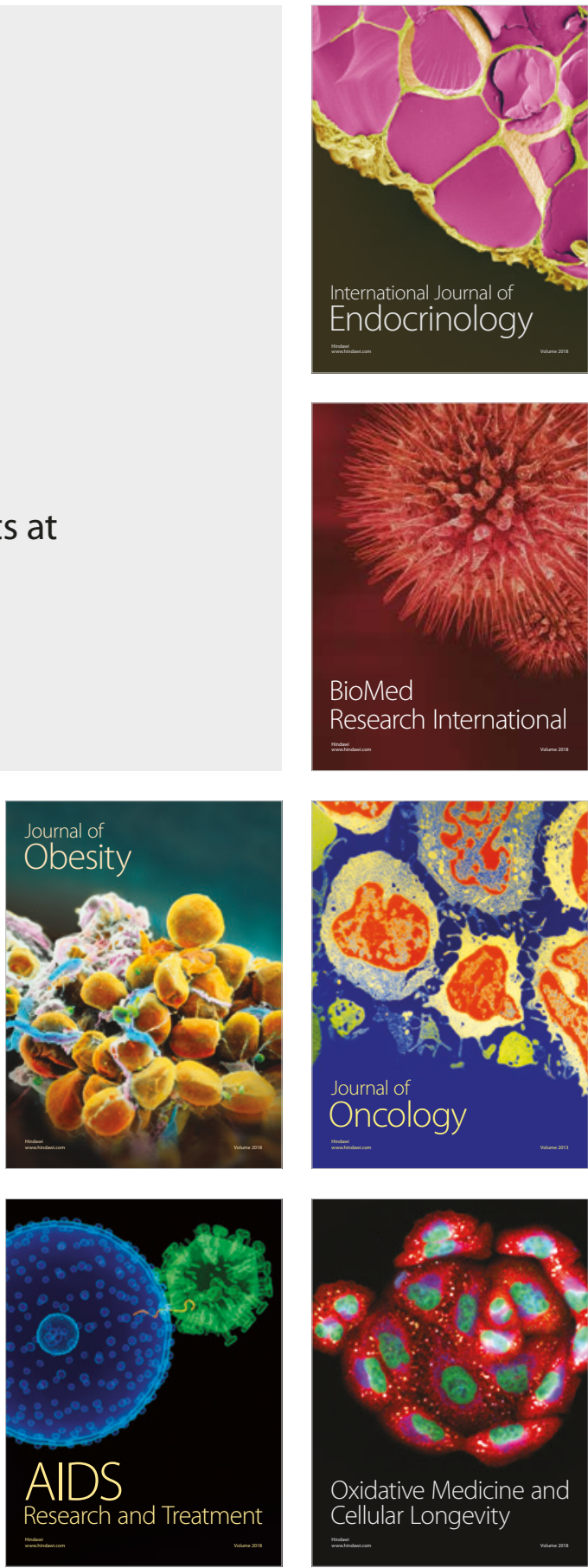